\title{
COMENTÁRIOS SOBRE A UNIVERSALIZAÇÃO DO ACESSO À INTERNET À LUZ DA LEI N. 12.965/2014 E DA EMENDA CONSTITUCIONAL N. 85/2015
}

\section{COMMENTS ON UNIVERSALIZATION OF INTERNET ACCESS REGARDING THE LAW N. 12.965/2014 AND THE CONSTITUTIONAL AMENDMENT N. 85/2015}

\begin{abstract}
FERNANDO DE BRITO ALVES
Pós-doutor em Democracia e Direitos Humanos pelo lus Gentium Conimbrigae da Faculdade de Direito da Universidade de Coimbra e pelo Centro de Estudos Interdisciplinares do Séc. XX da Universidade de Coimbra. Doutor em Direito pela Instituição Toledo de Ensino - ITE / Bauru-SP. Professor adjunto da UENP (Universidade Estadual do Norte do Paraná).
\end{abstract} fernandobrito@uenp.edu.br

JoÃo ÉdER FURLAN FERREIRA DE SOUZA Mestrando em Ciência Jurídica pela Universidade Estadual do Norte do Paraná (UENP). joaoeder@afs.adv.br

\section{RESUMO}

O surgimento da sociedade da informação, conforme conceito de Manuel Castells, no âmbito dos séculos XX e XXI transformou sobremaneira a forma de organização social, elevando a informação ao posto de protagonista em tempos onde cada vez mais relações são travadas no ambiente denominado por Pierre Lèvy como ciberespaço. Neste sentido, ainda que o cenário apontado pela mais recente pesquisa denominada "TIC Domicílios" seja o de aumento de adoção à Internet no âmbito residencial das diferentes regiões brasileiras, a desigualdade de tal adoção entre classes e regiões ainda se mostra como necessidade legítima para a atuação estatal. Desta forma, este trabalho analisa como tanto a Lei n. 12.965/2014, também denominada Marco Civil da Internet, quanto a Emenda Constitucional n. 85/2015 exercem papel fundamental na responsabilização estatal pela universalização do acesso à Internet, de forma a garantir a efetiva inclusão digital, permitindo a incursão do indivíduo na prática da cidadania de forma substancial.

Palavras-chave: Acesso à Internet; Emenda Constitucional n. 85/2015; Lei n. 12.965/2014; Responsabilidade do Estado.

\begin{abstract}
The emergence of the information society, as conceptualized by Manuel Castells, in the context of the twentieth and twenty-first centuries, greatly transformed the way of social organization, bringing information to the place of protagonist in times where more and more relations are established in the environment called by Pierre Lèvy as the cyberspace. With this in mind, although the scenario indicated by the most recent survey nominated "TIC Domicílios" is that Internet use increased at household level within different brazilian regions, the inequality of such use among classes and regions still shows how legitimate is the need for state action in this matter. Thus, this paper analyzes how the Law n. 12.965/2014, also known as the Brazilian Civil Rights Framework for the Internet, and the Constitutional Amendment $n$. $85 / 2015$ play a key role in state responsibility for the universalization of Internet access, in order to ensure an effective digital inclusion, enabling individuals to exercise citizenship in a substantial way.
\end{abstract}

Keywords: Internet access; Constitutional Amendment n. 85/2015; Law n. 12.965/2014; State responsibility. 


\section{SUMÁRIO}

INTRODUÇÃO; 10 SURGIMENTO DA SOCIEDADE DA INFORMAÇÃO E A EMERGENTE NECESSIDADE DO ACESSO Å INTERNET; 2 BREVE PANORAMA DA ADOÇ̃̃̃O DAS TECNOLOGIAS DA INFORMAÇÃÕ E COMUNICAÇÃO (TIC) NO ÂMBITO BRASILEIRO; 3 O MARCO CIVIL DA INTERNET E SUA REGULAMENTAÇÃO: A UNIVERSALIZAÇÃO DO ACESSO À INTERNET E A DELIMITAÇÃO DA "FUNÇÃO SOCIAL DA REDE"; 40 PAPEL DA EMENDA CONSTITUCIONAL N. 85/2015 E A CONSTITUCIONALIZAÇÃO DO DIREITO DE ACESSO À INTERNET; CONCLUSÃO; REFERÊNCIAS.

\section{INTRODUÇÃO}

0 presente estudo versa sobre a responsabilidade estatal pela universalização do acesso à Internet no contexto da lei n. 12.965/2014, também conhecida como Marco Civil da Internet, bem como da Emenda Constitucional n. 85/2015, com o escopo de concretização das garantias fundamentais sociais inerentes aos próprios benefícios advindos do acesso à Internet em si.

Em primeiro lugar, faz-se referência ao surgimento da sociedade da informação no contexto moderno, o que por si só gerou a necessidade da garantia do acesso informacional como forma de efetivação da autonomia individual no âmbito do surgimento do ciberespaço.

Após, delimita-se o cenário da desigualdade do acesso às Tecnologias da Informação e Comunicação (TIC), utilizando-se de breve análise da pesquisa realizada pelo Centro Regional de Estudos para o Desenvolvimento da Sociedade da Informação sob os auspícios da Unesco (CETIC.br) e denominada TIC Domicílios. Passa-se então a analisar as disposições do Marco Civil da Internet que fazem referência à universalização do acesso à Internet e seus desdobramentos, como, por exemplo, a função social da rede, fazendo menção à responsabilização estatal delimitada em seu Capítulo IV.

Por fim, faz-se menção à Emenda Constitucional n. 85/2015 e sua inovação no que se refere à delimitação de competências materiais e legislativas sobre o fomento do acesso às tecnologias e inovação, conferindo, por sua vez, dimensão constitucional à universalização do acesso à Internet. 


\section{O SURGIMENTO DA SOCIEDADE DA INFORMAÇÃO E A EMERGENTE NECESSIDADE DO ACESSO À INTERNET}

O conceito de "sociedade da informação" vem sendo utilizado como forma de substituição do conceito de "sociedade pós-industrial", agregando a este a ideia do paradigma de revolução tecnológica que vem se instalando nas últimas décadas. Expressa, então, o conjunto de transformações pelas quais passa a sociedade no sentido da dependência não mais de insumos baratos de energia (como na sociedade industrial), mas sim de informação, cujo acesso está intimamente ligado à proliferação das novas tecnologias como, por exemplo, a Internet. Este novo modo de organização mostrou-se inclusive primordial para a implementação de um importante processo de reestruturação do sistema capitalista no âmbito dos séculos XX e $X X I^{1}$.

Com o gradual alastramento da adoção da Internet nos mais variados âmbitos e contextos, sejam eles acadêmicos, domésticos ou (principalmente) empresariais, as possibilidades de comunicação antes restritas revelaram-se, então, cada vez mais amplas, plurais e acessíveis, consolidando-se assim uma nova estrutura social associada ao surgimento de um novo modo de desenvolvimento denominado informacionalismo.

Por outro lado, a veloz e crescente evolução da tecnologia eletrônica, influenciada sobretudo pelos enunciados da "Lei de Moore"2, termo computacional que remonta a 1970, contribuiu fundamentalmente para o rápido alastramento da Internet em âmbito mundial, sobretudo no período compreendido entre o final do século XX e início do século XXI, tendo em vista o surgimento de dispositivos cada vez menores e mais avançados, permitindo uma troca de dados mais rápida e, consequentemente, facilitou o acesso à rede mundial.

Neste particular, partindo-se para os tempos atuais, dominados pela ampla utilização da Internet nos mais variados contextos, a adoção cada vez maior de smartphones, tablets e dispositivos de computação vestível mostrou-se fundamental para que cada vez mais pessoas pudessem usufruir do amplo acesso à informação, em grande parte graças à tecnologia de acesso pelos dados móveis.

\footnotetext{
${ }^{1}$ CASTELLS, Manuel. A sociedade em rede. São Paulo: Paz e Terra, 1999.

2 MOORE'S LAW. Moore's Law: How overall processing power for computers will double every two years, [2009?]. Disponível em: <http: //www.mooreslaw.org/>. Acesso em: 11 nov. 2015.
} 
Não obstante, caminha-se para um paradigma importante dominado pelo moderno conceito da Internet of Things (IOT, ou "Internet das Coisas”), cuja premissa é a possibilidade de conexão à rede mundial de toda e qualquer "coisa" (no seu sentido efetivamente amplo) com o potencial de aumento de sua funcionalidade pela conexão à Internet. Já é de amplo conhecimento a possibilidade de conexão à Internet por imóveis (pela automação residencial), eletrodomésticos, veículos, e demais produtos que certamente constituem um rol apenas exemplificativo.

Vê-se que as trocas de dados e informações passaram, então, a se realizar em velocidades antes inimagináveis, transformando a Internet em verdadeiro meio de comunicação e convivência, interligando dezenas de milhões de computadores, celulares e outros dispositivos em âmbito mundial, permitindo desta forma o acesso rápido e fácil a uma quantidade de informações praticamente inesgotáveis, anulando, assim, toda distância de lugar e tempo.

Percebe-se que a Internet exerce, portanto, papel fundamental no desenvolvimento dos mais variados contextos, desde o âmbito econômico, educacional, relativo à saúde, até o cultural, vários dos quais pressupostos para a garantia e manutenção dos direitos fundamentais sociais. Neste diapasão, o surgimento e recente consolidação da denominada sociedade digital, como visto na obra de Pinheiro ${ }^{3}$, delimita a concretização de deveres e principalmente direitos insertos no novo contexto da contemporaneidade. Como exemplo pode-se citar o direito ao acesso à informação de interesse público na seara digital que, de acordo com Alves", é "sem dúvida um dos principais pilares das democracias contemporâneas".

No centro de tal sociedade a informação ocupa o lugar de matéria-prima, vez que o ser humano passa a utilizar a tecnologia per si para a atuação na informação stricto sensu, possibilitando a alta penetrabilidade das novas tecnologias no contexto social, face à inerência da informação em toda e qualquer atividade humana, seja ela individual ou coletiva. Continuando na esteira do pensamento de Castells, a flexibilidade dos processos de organização social é mais uma das características marcantes da sociedade da informação ${ }^{5}$, facilitada pelo predomínio da lógica de redes que, por sua vez, atua de forma decisiva na convergência cada vez mais crescente das tecnologias, interligando as diversas áreas do saber.

\footnotetext{
${ }^{3}$ PINHEIRO, Patrícia Peck. Direito Digital. 4 ed. São Paulo: Saraiva, 2010.

${ }^{4}$ ALVES, Fernando de Brito. Constituição e participação popular: a construção histórico-discursiva do conteúdo jurídico-político da democracia como direito fundamental. Curitiba: Juruá, 2013.

${ }^{5}$ CASTELLS, Manuel. A sociedade em rede. São Paulo: Paz e Terra, 1999.
} 
Com o protagonismo da informação como "matéria-prima” no processo da transformação social, constitui-se o ciberespaço, composto pelo “conjunto dos sistemas de comunicação eletrônicos, na medida em que transmitem informações provenientes de fontes digitais ou destinadas à digitalização, como visto na obra de Lèvy ${ }^{6}$. A informação é, portanto, virtual - plástica, fluida, interativa, calculável com precisão e tratável em tempo real - sendo que tal característica constitui-se como a marca distintiva do ciberespaço, nas palavras do mesmo autor. Assim, o ciberespaço passa a ser o meio default para a comunicação e suporte de memória da humanidade no século XXI.

É neste contexto que surge a real possibilidade de constituir-se o advento do ciberespaço como fonte de exclusão social. Trata-se de uma forma de desigualdade tanto entre “classes" sociais - ricos e pobres - quanto entre nações inteiras, frente à clara disparidade que se vê de investimentos estatais em infraestrutura, valores praticados no tocante aos planos que possibilitam a conexão à Internet, qualidade e estabilidade de tais serviços entre outros fatores. Neste sentido a lição de Boaventura de Sousa Santos:

Hoy es innegable la hegemonía de los derechos humanos como lenguaje de la dignidad humana. Sin embargo, esta hegemonía debe convivir con una realidad alarmante. La gran mayoría de la población mundial no es sujeto de derechos humanos, sino el objeto de los discursos de derechos humanos. Por tanto, hay que comenzar por preguntarse si los derechos humanos son eficaces para la lucha de los excluidos, los explotados y los discriminados, o si, por el contrario, la hacen más difícil. En otras palabras, ¿la hegemonía de la que goza hoy el discurso de los derechos humanos es el resultado de una victoria histórica o, por el contrario, de una derrota histórica? ${ }^{7}$

Considerando, neste sentido, não só a possibilidade, mas a real probabilidade de consequente incentivo à referida exclusão social frente aos fatores supramencionados, uma vez que inúmeros benefícios surgem da utilização da Internet como potencial de transformador social - verbi gratia a possibilidade de igualdade de participação ativa dos processos de inteligência coletiva, de valorização da cultura, de fornecimento de competências pessoais e aumento da autonomia das pessoas ou grupos envolvidos no ciberespaço, como se vê na obra de Bonilla $^{8}$ - torna-se necessária a intervenção estatal para a garantia de que tais benefícios sejam efetivamente sentidos nas camadas sociais que mais necessitam deles, sob pena de incursão num

\footnotetext{
${ }^{6}$ LÉVY, Pierre. Cibercultura: tradução de Carlos Irineu da Costa. São Paulo: ed. 34, 1999.

${ }^{7}$ DE SOUSA SANTOS, Boaventura. Derechos humanos, democracia y desarollo. Bogotá: Centro de Estudios de Derecho, Justicia y Sociedad, Dejusticia, 2014.

${ }^{8}$ BONILLA, Maria Helena Silveira; PRETTO, Nelson de Luca. Inclusão digital: polêmica contemporânea. Salvador: EDUFBA, 2011.
} 


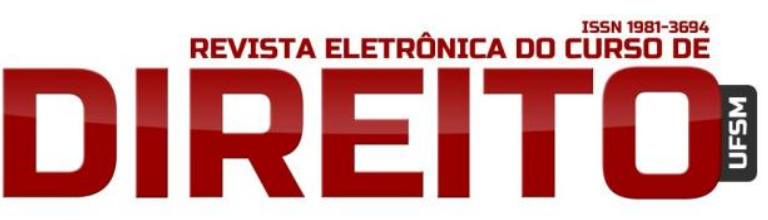

COMENTÁRIOS SOBRE A UNIVERSALIZAÇÃO DO ACESSO À INTERNET À LUZ DA LEI N. 12.965/2014 E DA EMENDA CONSTITUCIONAL N. 85/2015

FERNANDO DE BRITO ALVES JoÃo ÉdER FURLAN FERREIRA DE SOUZA

mero discurso de direitos humanos ineficaz. Tal necessidade constitui o núcleo da ideia de inclusão digital - que não é alcançada pela mera possibilidade de acesso à Internet, mas sim pela utilização da mesma como catalisadora da incursão do indivíduo na prática do pleno exercício de sua cidadania.

\section{BREVE PANORAMA DA ADOÇÃO DAS TECNOLOGIAS DA INFORMAÇÃO E COMUNICAÇÃO (TIC) NO ÂMBITO BRASILEIRO}

Com o objetivo de delimitar o panorama brasileiro de adoção às Tecnologias da Informação e Comunicação (TIC), sob vistas de estabelecer a importância da responsabilidade estatal na provisão de acesso à Internet, faz-se necessário tecer algumas considerações no sentido das pesquisas que vêm sendo realizadas, sobretudo no âmbito brasileiro. Neste sentido, anualmente, o Centro Regional de Estudos para o Desenvolvimento da Sociedade da Informação sob os auspícios da Unesco (CETIC.br), órgão ligado ao Núcleo de Informação e Coordenação do Ponto BR (NIC.br) e ao Comitê Gestor da Internet no Brasil (CGI.br), elabora a pesquisa denominada "TIC Domicílios", com o objetivo de medir, entre outros, o uso das tecnologias da informação e da comunicação nos domicílios, o acesso individual a computadores e à Internet bem como as atividades desenvolvidas na rede.

De acordo com a última edição ${ }^{9}$, lançada em setembro de 2015 , cresceu a quantidade de pessoas com 10 anos ou mais cujo acesso à Internet se deu por meio do celular. Tal percentual triplicou nos últimos três anos, sendo que saltou de 15\% em 2011 para 47\% em 2014, o que representa a quantidade de 81,5 milhões de pessoas. Neste sentido, o percentual de brasileiros de 10 anos ou mais que são usuários de internet chegou a 55\%, o que corresponde a 94,2 milhões de usuários.

Apesar do rápido crescimento do uso da Internet pelo celular em todas as classes sociais, a pesquisa aponta a persistência da desigualdade no acesso à Internet no país, tendo em vista os patamares mais reduzidos verificados nas áreas rurais e sobretudo nas regiões Norte e Nordeste. Considerando a realização do estudo em mais de 19 mil domicílios brasileiros, entre outubro de 2014 e março de 2015, verificou-se que as desigualdades por classe social e área ainda persistem: enquanto na classe "A" a proporção de domicílios com acesso à Internet é de

${ }^{9}$ CETIC.BR. Pesquisas e indicadores. Disponível em: <http://cetic.br/pesquisas/>. Acesso em: 12 nov. 2015. 
98\%, a classe "B" dispõe de 82\%; a classe “C”, por sua vez, de $48 \%$ e, por fim, entre as classes “D” e "E”, 14\%. Nas áreas urbanas, a proporção de domicílios com acesso à Internet é de 54\%, enquanto nas áreas rurais é de $22 \%$.

Ainda que em 2014 as conexões residenciais mediante telefonia celular tenham sido aglutinadas ao conceito de acesso domiciliar à Internet, o contexto brasileiro ainda encontra desafios para a universalização do acesso à Internet no âmbito dos domicílios. Pela análise histórica da TIC Domicílios, verifica-se preliminarmente a permanência da desigualdade no acesso, fato complexo que delimita a necessidade da atuação estatal para a efetivação dos necessários avanços neste sentido.

\section{O MARCO CIVIL DA INTERNET E SUA REGULAMENTAÇÃO: A UNIVERSALIZAÇÃO DO ACESSO À INTERNET E A DELIMITAÇÃO DA “FUNÇÃO SOCIAL DA REDE”}

Em um contexto no qual as diferenças culturais e institucionais não apenas estão presentes, mas principalmente se intensificam à medida que o acesso à informação se demonstra de acordo com a capacidade econômica do ente social, sobretudo pelas motivações constantes do capítulo anterior, constitui-se um momento histórico em que "por todo o mundo redes globais de riqueza e poder conectam pontos nodais e valorizam os indivíduos em todo o planeta, embora desconectem e excluam grandes segmentos das sociedades, regiões e até países inteiros". ${ }^{10}$

Surge, então, a Lei n. 12.965/2014, oriunda de um processo de consulta iniciado em meados de 2010 pelo Ministério da Justiça brasileiro com a finalidade de construção colaborativa de um marco regulatório da Internet no Brasil, de forma a conceder direitos e delimitar deveres inerentes à utilização da Internet tanto aos usuários quanto aos provedores, não se olvidando do poder público. Tal processo consolidou-se em duas fases de discussão e elaboração, sendo característica marcante o incentivo "metalinguístico" do debate acerca do tema pela via digital - vez que grande parte do processo de elaboração aconteceu na própria plataforma online denominada "Cultura Digital”11, de iniciativa do Ministério da Cultura. Possibilitou-se, desta

${ }^{10}$ CASTELLS, Manuel, op. cit.

11 CULTURA DIGITAL. Marco Civil da Internet: Seus direitos e deveres em discussão. Disponível em: <http://culturadigital.br/marcocivil/>. Acesso em: 11 nov. 2015. 
forma, que a construção daquilo que viria a se consolidar no Marco Civil da Internet fosse efetivamente plural, englobando, por exemplo, usuários comuns, representantes da iniciativa privada, parlamentares, comunidade técnica, representantes do governo e demais interessados, de forma que se englobasse o maior número possível de demandas sociais compatíveis entre si.

Neste sentido, considerando que uma de tais principais demandas sociais consiste na necessidade do efetivo acesso à Internet, o artigo $2^{\circ}$, inciso II da referida lei fixa como um dos fundamentos da disciplina e uso da Internet no Brasil "os direitos humanos, o desenvolvimento da personalidade e o exercício da cidadania em meios digitais", enquanto caracteriza-se como pressuposto, pelo inciso VI do mesmo artigo, a "finalidade social da rede". De outro turno, o artigo $3^{\circ}$, inciso $\mathrm{V}$ estabelece que tal acesso deve ser regido pela preservação da "estabilidade, segurança e funcionalidade da rede", refletindo-se no dever de manutenção e evolução da infraestrutura necessária para a garantia de tais características, como adiante se demonstra.

0 artigo $4^{\circ}$ do Marco Civil prevê, em seu inciso I, “o direito de acesso à Internet a todos" como objetivo da disciplina do uso da Internet no Brasil, disposição que se reveste de importantíssimo caráter para a concretização de todas as outras garantias estabelecidas na mesma lei. 0 inciso II do artigo $4^{\circ}$, por sua vez, estabelece como outro objetivo "o acesso à informação, ao conhecimento e à participação na vida cultural e na condução dos assuntos públicos", enquanto que o inciso III do referido artigo caracteriza a "inovação e o fomento à ampla difusão de novas tecnologias e modelos de uso e acesso" como mais um dos objetivos. Tais disposições demonstram, então, a incontroversa responsabilidade estatal pela concretização de tais deveres.

Da mesma forma, delimita-se, no artigo $6^{\circ}$ do mesmo diploma legal, a importância da rede para a promoção do "desenvolvimento humano, econômico, social e cultural”. 0 artigo $7^{\circ}$ aduz que o acesso à Internet é "essencial ao exercício da cidadania”, sendo que seus incisos IV e $\checkmark$ garantem a prestação continuada e qualificada, respectivamente, do serviço de Internet. Não é necessário esforço algum, portanto, para verificar a preocupação latente com a garantia de que a Internet permeasse cada vez mais a sociedade brasileira, de forma a propagar seus benefícios nas diversas regiões do país.

Prosseguindo na análise das disposições da referida lei, esta não olvidou de estabelecer diretrizes para a atuação estatal, o que fica claramente delimitado no âmbito do Capítulo IV, intitulado “Da atuação do Poder Público". Imputam-se, desta forma, obrigações ao Poder Público para a efetiva garantia da "função social" do Marco Civil da Internet. Se houvesse qualquer dúvida neste sentido, sanar-se-ia a mesma facilmente pela análise do artigo 24 , que 
logo em seu caput fixa a competência do desenvolvimento da Internet no Brasil a todos os entes federativos concorrentemente - União, Estados, Distrito Federal e Municípios.

Seu inciso I determina o estabelecimento de "mecanismos de governança multiparticipativa, transparente, colaborativa e democrática”, devendo necessariamente existir a participação de entes governamentais, do setor empresarial, da sociedade civil e da comunidade acadêmica. Trata-se do modelo multistakeholder (multissetorial) de governança da Internet, atualmente defendido em âmbito mundial como a melhor solução para manutenção do caráter livre e aberto da Internet, necessário para a manutenção da fidelidade à sua proposta originária. A importância de tal disposição reside na possibilidade plural de discussão e fiscalização de todas as atividades relativas ao fornecimento de acesso à Internet, sejam elas da iniciativa pública ou privada.

O inciso VII do mesmo artigo, por sua vez, delimita o dever de “otimização da infraestrutura das redes e estímulo à implantação de centros de armazenamento, gerenciamento e disseminação de dados no País, promovendo a qualidade técnica, a inovação e a difusão das aplicações de Internet, sem prejuízo à abertura, à neutralidade e à natureza participativa”. Faz referência, portanto, à necessidade de evolução contínua da infraestrutura que possibilite a melhoria progressiva do fornecimento de acesso à Internet, tudo para a concretização do disposto no artigo $7^{\circ}, \mathrm{V}$ do mesmo diploma legal acima referenciado. Vê-se, portanto, que a intenção legislativa neste caso em concreto é de atribuir ao Poder Público, em suas várias instâncias e de forma concorrente, a melhoria gradativa da infraestrutura das redes no âmbito brasileiro.

Por outro lado, fala-se no inciso VIII do artigo em estudo sobre o "desenvolvimento de ações e programas de capacitação para uso da Internet", bem como a "promoção da cultura e da cidadania" no tocante ao inciso IX. Neste sentido, necessária a referência de que tais programas podem incluir políticas de pontos públicos gratuitos de acesso à Internet (também conhecidos como telecentros), redes livres e de capacitação/formação, em parceria com organizações da sociedade civil, tudo para fins da melhor eficácia da implementação de tais políticas, sempre com a finalidade máxima da efetiva promoção da cidadania.

Por fim, o inciso $X$ do artigo 24 do Marco Civil delimita o dever de "prestação de serviços públicos de atendimento ao cidadão de forma integrada, eficiente, simplificada e por múltiplos canais de acesso". Faz-se referência, portanto, aos serviços delimitados como e-gov, com previsões de mecanismos de controle e participação social, devendo-se observar a previsão legal constante no inciso $\mathrm{V}$ do mesmo artigo, qual seja a "adoção preferencial de tecnologias, 
padrões e formatos abertos e livres", possibilitando um custo menor que contribua para a universalização do acesso à Internet neste particular.

Necessária a menção ao artigo 26 da mesma lei, que delimita ao Poder Público o dever de "capacitação, integrada a outras práticas educacionais, para o uso seguro, consciente e responsável da internet como ferramenta para o exercício da cidadania, a promoção da cultura e o desenvolvimento tecnológico", disposição importantíssima para assegurar que o fornecimento de acesso à Internet efetivamente concretize a autonomia das pessoas envolvidas no ciberespaço, tornando-as atuantes - e não "atuadas", como visto em Castells (2000).

Por último, mas não menos determinante, no artigo 27 do Marco Civil fala-se do dever das iniciativas públicas de fomento à cultura digital e de promoção da Internet como ferramenta social, em seu inciso I, de "promover a inclusão digital", bem como de "reduzir as desigualdades, sobretudo entre as diferentes regiões do País, no acesso às tecnologias da informação e comunicação e no seu uso", conforme seu inciso II.

Neste sentido, segundo Azevedo:

\begin{abstract}
A realização da inclusão digital pressupõe a instituição de políticas públicas pelo governo, sendo fundamental, para tanto, um diagnóstico bem elaborado sobre as necessidades informacionais. Em seguida, como pontua Suaiden, com o auxílio de técnicas de tomada de decisão, deve-se elaborar um planejamento estratégico compatível com a realidade social. Ao disciplinar o acesso às novas formas de comunicação, o Poder Público deve ter, como objetivo principal, possibilitar o exercício da cidadania à toda população, em especial, buscar o respeito pelo direito de informação. ${ }^{12}$
\end{abstract}

Com efeito, o Marco Civil da Internet fora regulamentado mediante a edição do Decreto n. 8771/2016, publicado em 11 de maio de 2016 e com vacatio legis de 30 dias.

Apesar do ato da publicação ter sido feito às pressas pela então presidente Dilma Rouseff (face a seu iminente afastamento por força do processo de impedimento), salienta-se que mencionado decreto fora objeto de consulta pública perante a plataforma online ${ }^{13}$ do Ministério da Justiça em duas fases: a primeira, realizada entre 28 de janeiro e 30 de abril de 2015, acolheu comentários e propostas sobre quatro eixos temáticos (neutralidade de rede, guarda de registros, privacidade na rede e outros temas e considerações); ao passo em que a segunda fase visou a construção colaborativa de uma minuta de decreto. No fim das contas,

\footnotetext{
${ }^{12}$ AZEVEDO, Ana. Marco civil da internet no Brasil. Rio de Janeiro: Alta Books, 2014.

${ }^{13}$ MINISTÉRIO DA JUSTIÇA. Pensando o Direito. Disponível em: <http://pensando.mj.gov.br/marcocivil/>. Acesso em: 05 jul. 2016.
} 
mencionado decreto abordou pontos de extrema importância para a manutenção do caráter neutro, universal e inclusivo da Internet.

Um dos principais pontos, que neste trabalho se faz necessário mencionar, faz referência a não discriminação no tráfego de pacote de dados (em sede do princípio da neutralidade de rede, garantido pelo artigo $9^{\circ}$ do Marco Civil). Tal princípio, correntemente associado à obra de Tim Wu, garante que o acesso à Internet não priorize determinada aplicação em detrimento de outra ${ }^{14}$. Neste sentido, nos termos do Marco Civil e sua regulamentação via Decreto, nenhum provedor de aplicação ou de conexão, por exemplo, terá a prerrogativa do oferecimento de quaisquer produtos ou serviços para determinados usuários em detrimento de outros.

Entretanto, tal negativa admite exceções. 0 tráfego de dados poderá ser discriminado, ou seja, tratado de forma diferencial, por exemplo, desde que em casos técnicos indispensáveis ou quando necessário para a priorização de serviços de emergência (conforme artigos $3^{\circ}$ e seguintes do Decreto n. 8771/16). Interessante notar, neste sentido, que a neutralidade de rede é aqui considerada fundamental para o acesso universal à Internet, conforme trata o caput do mencionado dispositivo legal:

Art. $3^{\circ} \mathrm{A}$ exigência de tratamento isonômico de que trata 0 art. $9^{\circ}$ da Lei $\mathrm{n}^{\circ}$ 12.965, de 2014, deve garantir a preservação do caráter público e irrestrito do acesso à internet e os fundamentos, princípios e objetivos do uso da internet no País, conforme previsto na Lei n 12.965, de 2014.

O Decreto, por sua vez, não se restringiu a regulamentar somente a neutralidade de rede, mas também outras questões que extrapolam o objetivo desde trabalho. Dentre outras proposições, mencionam-se, neste particular, aquelas de Artigo 19 et al. ${ }^{15}$, que, dentre outros, propôs “a institucionalização de estruturas de participação social referentes a políticas de desenvolvimento da Internet, consonantes com a intensa mobilização para a formulação do Marco Civil da Internet”. Fazem menção, ao mesmo tempo, à "revisão da experiência do que foi o Plano Nacional de Banda Larga", sugerindo que eventuais e futuros programas concernentes,

\footnotetext{
14 "The argument for network neutrality must be understood as a concrete expression of a system of belief about innovation, one that has gained significant popularity over last two decades. The belief system goes by many names." WU, Tim. Network Neutrality, Broadband Discrimination. Journal of Telecommunications and High Technology Law. Disponível em: <http://ssrn.com/abstract=388863>. Acesso em: 05 jul. 2016.

${ }^{15}$ ARTIGO 19 et al. Regulamentação do Marco Civil da Internet: considerações para o eixo "Políticas de Desenvolvimento da Internet". Disponível em: <http://artigo19.org/wpcontent/uploads/2015/03/propostasmcidigital.pdf>. Acesso em: 22 nov. 2015.
} 
como o "Banda Larga para Todos”, estabeleçam a prestação em regime público do serviço de telecomunicações que dá suporte ao acesso à Internet, garantindo-se a universalização do mesmo.

Portanto, nota-se que a promoção do uso da Internet enfrenta obstáculos em basicamente três eixos: a ampliação da disponibilidade de acesso à Internet (oferta de infraestrutura, como equipamentos, sinal e etc); o incentivo ao desenvolvimento e à disponibilização de conteúdos que atendam aos requisitos de acessibilidade, usabilidade e inteligibilidade e a capacitação da população, de modo a gerar interesse por tais tecnologias e despertar a confiança nesses potenciais usuários, constituindo assim verdadeira educação digital.

O papel do Marco Civil da Internet, neste sentido, é o de viabilizar o exercício do direito de informação da população - matéria-prima da sociedade da informação - pela via da promoção da inclusão digital, alcançada tão somente pela atuação do Estado no fornecimento do acesso à Internet conforme as diretrizes estabelecidas na mesma lei. Os primeiros - e efetivos - passos têm sido dados nessa direção, pela própria aprovação do Marco Civil, no ano de 2014, bem como do Decreto que o regulamenta, este já em 2016. Há, entretanto, um longo caminho a perseguir.

\section{PAPEL DA EMENDA CONSTITUCIONAL N. 85/2015 E A CONSTITUCIONALIZAÇÃO DO DIREITO DE ACESSO À INTERNET}

Após breves considerações sobre as disposições constantes do Marco Civil da Internet, aliadas à de sua regulamentação (no que tange à neutralidade de rede), faz-se necessário mencionar a Emenda Constitucional n. 85, de 26 de fevereiro de 2015, vez que também delimitou a competência do Poder Público, de forma concorrente em todas as suas esferas, para a provisão de tal acesso. Isto porque a Constituição Federal de 1988 preocupou-se tanto com o desenvolvimento científico como com a pesquisa e a capacitação tecnológicas, impondo a responsabilidade estatal, nos termos dos artigos 218 e 219 , de promoção e incentivo dos mesmos. Conforme a lição de Canotilho et al.:

Capacitação é um processo educativo para adquirir competências, habilidades e técnicas, formação (ensino) e aperfeiçoamento de recursos humanos em tecnologia (logo, em ciência). Para Ives Gandra Martins (p. 849), capacitação tecnológica é "a habilitação das pessoas para o exercício dos avanços 
tecnológicos, para seu uso e para seu proveito". Para Cretella Jr. (p. 4486), é “a possibilidade, idoneidade ou aptidão que uma dada indústria, empresa ou instituto apresenta no emprego de técnicas e processos modernos para atingir seus fins". Capacitar é um neologismo que significa ensinar, formar, atualizar, aperfeiçoar pessoas (recursos humanos nas universidades, institutos e empresas), no caso, em tecnologia. Dos três focos ou diretrizes do caput do art. 218, este parece ser o mais fraco, mas complementado pelos $\S \S 3^{\circ}, 4^{\circ}$ e $5^{\circ}$ (e mesmo pelo $\S$ $2^{\circ}$ sobre pesquisa tecnológica). Por força do $\S 4^{\circ}$ observa-se que esta capacitação (formação e aperfeiçoamento), se, em relação à pesquisa tecnológica, deve também contribuir para o objetivo constitucional, o desenvolvimento do "sistema produtivo nacional e regional" e a "solução dos problemas brasileiros". ${ }^{16}$

Desta feita, é elementar o papel tanto da ciência, como da tecnologia e da inovação no desenvolvimento econômico do país, vez que pressupostos da geração de empregos. Por isso, a pesquisa científica básica e tecnológica deve ser objeto de tratamento elementar do Estado.

Neste diapasão, a Emenda Constitucional n. 85/2015, originada da PEC 290/2013, reforçou o dever de atuação do Estado no campo da Ciência e da Tecnologia, inserindo na seara constitucional o dever estatal de promoção da inovação e de políticas públicas que incentivem, além do desenvolvimento científico, a pesquisa e a capacitação científica e tecnológica.

Seu surgimento se deu no contexto de esgotamento de estratégias tradicionais que pudessem estimular o desenvolvimento tanto em âmbito econômico, quanto no âmbito social. Em tempos de estagnação do setor produtivo, face o modelo de financiamento à produção mediante aporte de capital de fundos de pensão e instituições financeiras públicas.

É incontroversa a importância da inovação no âmbito do setor produtivo. Os bens de inovação, da mesma forma, caracterizam-se por constituírem-se, por exemplo, de nãorivalidade $^{17}$ (a característica de não impedimento da utilização ou consumo do bem por outrem quando usado ou consumido por alguém) e não-exclusividade (a impossibilidade de impedimento da utilização de tal bem).

Por tal conjuntura, vê-se que a simples disposição mercantil do livre mercado não é capaz para a garantia da criação e manutenção do fluxo de investimento em determinada tecnologia, barrando-se, dessa forma, o processo de inovação. A atuação estatal não pode se furtar, neste particular, de investir e estimular o desenvolvimento industrial e, sobretudo, o

${ }^{16}$ CANOTILHO, J. J. Gomes et al. (Coords.). Comentários à Constituição do Brasil. São Paulo: Saraiva/Almedina, 2013.

${ }_{17}$ BARBOSA, Denis Borges. Direito ao desenvolvimento, inovação e a apropriação das tecnologias após a Emenda Constitucional no. 85. Disponível em: <http://www.denisbarbosa.addr.com/ arquivos/200/inovacao/direito_ao_desenvolvimento_2015.pdf>. Acesso em: 05 jul. 2016. 
tecnológico, sob pena de incorrer a economia de determinada nação em graves riscos de subdesenvolvimento, afetando-a, além disso, em seus meios sociais e econômicos.

No âmbito brasileiro, a EC n. 85/2015 altera uma série de dispositivos constitucionais, dentre eles os artigos 218 e 219, regulados e aplicados nas situações em concreto mediante a Lei n. 10.973/2004, introduzindo-se o verbete “inovação" no texto constitucional, além de uma série de outras medidas.

Por força da mesma Emenda, ampliou-se a competência material da União, dos Estados, do Distrito Federal e dos Municípios, compreendendo a responsabilidade solidária de todos os entes na promoção dos meios de acesso, à tecnologia, à pesquisa e à inovação, adicionando tais meios aos dispostos anteriormente, quais sejam cultura, educação e ciência, consorte o disposto no artigo 23, V da Constituição Federal.

Da mesma forma, a Emenda ampliou a competência legislativa concorrente da União, dos Estados e do Distrito Federal para compreender a responsabilidade de tais entes de legislar concorrentemente não apenas sobre educação, cultura, ensino e desporto, inserindo os campos da ciência, da tecnologia, da pesquisa, do desenvolvimento e da inovação, conforme o artigo. 24, IX da Magna Carta.

Neste sentido, sendo incontroversa a responsabilidade do Estado - quais sejam a União, os Estados, o Distrito Federal e os Municípios - na promoção e também no incentivo do desenvolvimento nacional, consorte o artigo $3^{\circ}$, II da Constituição Federal, não se é difícil associar a ideia da promoção do acesso à Internet como um dos pressupostos de caracterização de tal desenvolvimento, sobretudo no âmbito dos processos de inovação agora consolidados pela EC n. 85/2015.

Veemente que tais disposições da Emenda Constitucional n. 85/2015 vieram apenas corroborar a disposição do artigo 24 do Marco Civil da Internet, regulamentado pelo Decreto n. 8771/2016, revestindo tal dispositivo de força constitucional, tudo pelo próprio caráter de inovação da tecnologia de conexão às redes, restando delimitada a responsabilidade de todos os entes federativos na colaboração para o fornecimento de instrumentos estatais que incentivem a provisão de acesso à Rede no âmbito brasileiro, tudo para fins da efetiva promoção da inclusão digital por meio da universalização do acesso à Internet. 


\section{CONCLUSÃO}

O moderno contexto da sociedade da informação no âmbito do final do século $X X$ e início do século XXI trouxe à tona modificações profundas pela crescente adoção das tecnologias de informação e comunicação, delas emergindo novas relações e necessidades sociais. Neste contexto, o alastramento da Internet em escala mundial permitiu a conversão da informação em matéria-prima fundamental para o desenvolvimento não só econômico, mas também social.

Neste sentido, considerando o contexto brasileiro de desigualdade no que se refere à adoção e fornecimento do acesso à Internet, ainda que o cenário seja de progressivas melhorias nos últimos anos, é elementar o papel que o Marco Civil da Internet exerce, sobretudo por meio de seu Capítulo IV, no sentido de garantir a universalização do acesso à Internet ao delimitar a responsabilidade por ela de forma solidária a todos os entes federativos.

Da mesma forma, é incontroverso o papel fundamental da Emenda Constitucional $\mathrm{n}$. 85/2015 na consolidação de tal universalização, vez que inseriu no corpo constitucional a responsabilidade estatal solidária, mais uma vez, em todos os âmbitos da Administração pela promoção dos meios de acesso à tecnologia.

Destarte, tais comandos legais constituem importante progresso no sentido da garantia da efetiva inclusão digital por meio da universalização do acesso à Internet, com o fim máximo de promover a real inclusão social, inserindo na sociedade, outrossim, a parcela da população acometida pelas desigualdades sociais, empoderando, por fim, a mesma, de forma a possibilitar o exercício efetivo e igualitário de sua plena cidadania.

\section{REFERÊNCIAS}

ALVES, Fernando de Brito. Constituição e participação popular: a construção históricodiscursiva do conteúdo jurídico-político da democracia como direito fundamental. Curitiba: Juruá, 2013.

ARTIGO 19 et al. Regulamentação do Marco Civil da Internet: considerações para o eixo "Políticas de Desenvolvimento da Internet". Disponível em: <http: / /artigo19.org/wpcontent/uploads/2015/03/propostasmcidigital.pdf>. Acesso em: 22 nov. 2015.

AZEVEDO, Ana. Marco civil da internet no Brasil. Rio de Janeiro: Alta Books, 2014.

BARBOSA, Denis Borges. Direito ao desenvolvimento, inovação e a apropriação das tecnologias após a Emenda Constitucional no. 85. Disponível em 


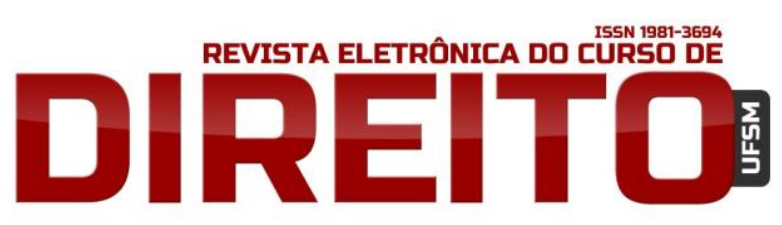

COMENTÁRIOS SOBRE A UNIVERSALIZAÇÃO DO ACESSO À INTERNET À LUZ DA LEI N. 12.965/2014 E DA EMENDA CONSTITUCIONAL N. 85/2015

FERNANDO DE BRITO ALVES JOÃo ÉdER FURLAN FERREIRA DE SOUZA

<http://www.denisbarbosa.addr.com/arquivos/200/inovacao/direito_ao_desenvolvimento_2015 .pdf>. Acesso em: 05 jul. 2016.

BONILLA, Maria Helena Silveira; PRETTO, Nelson de Luca. Inclusão digital: polêmica contemporânea. Salvador: EDUFBA, 2011.

BRASIL. Constituição (1988). Constituição da República Federativa do Brasil, de 5 de outubro de 1988. Disponível em: <http://www.planalto.gov.br/ccivil_03/Constituicao/Constituicao.htm>. Acesso em: 15 nov. 2015.

BRASIL. Constituição (1988). Emenda Constitucional $n^{\circ}$ 85, de 26 de fevereiro de 2015. Altera e adiciona dispositivos na Constituição Federal para atualizar o tratamento das atividades de ciência, tecnologia e inovação. Disponível em:

<http://www.planalto.gov.br/ccivil_03/constituicao/Emendas/Emc/emc85.htm>. Acesso em: 15 nov. 2015.

BRASIL. Marco Civil da Internet. Lei n. 12.965, de 23 de abril de 2014. Disponível em: < http://www.planalto.gov.br/ccivil_03/_ato2011-2014/2014/lei/l12965.htm>. Acesso em: 11 nov. 2015.

CASTELLS, Manuel. A sociedade em rede. São Paulo: Paz e Terra, 1999.

CANOTILHO, J. J. Gomes et al. (Coords.). Comentários à Constituição do Brasil. São Paulo: Saraiva/Almedina, 2013.

CETIC.BR. Pesquisas e indicadores. Disponível em: <http://cetic.br/pesquisas/>. Acesso em: 12 nov. 2015.

DE SOUSA SANTOS, Boaventura. Derechos humanos, democracia y desarollo. Bogotá: Centro de Estudios de Derecho, Justicia y Sociedad, Dejusticia, 2014.

LÉVY, Pierre. Cibercultura: tradução de Carlos Irineu da Costa. São Paulo: ed. 34, 1999.

CULTURA DIGITAL. Marco Civil da Internet: Seus direitos e deveres em discussão. Disponível em: <http://culturadigital.br/marcocivil/>. Acesso em: 11 nov. 2015.

MINISTÉRIO DA JUSTIÇA. Pensando o Direito. Disponível em:

<http://pensando.mj.gov.br/marcocivil/>. Acesso em: 05 jul. 2016.

MOORE'S LAW. Moore's Law: How overall processing power for computers will double every two years, [2009?]. Disponível em: <http://www.mooreslaw.org/>. Acesso em: 11 nov. 2015.

PINHEIRO, Patrícia Peck. Direito Digital. 4. ed. São Paulo: Saraiva, 2010.

WU, Tim. Network Neutrality, Broadband Discrimination. Journal of Telecommunications and High Technology Law. Disponível em: <http://ssrn.com/abstract=388863>. Acesso em: 05 jul. 2016.

Recebido em: 16/02/2016 / Revisões requeridas em: 29/06/2016 / Aprovado em: 08/07/2016 